\title{
DRIE REIZEN NAAR CURAÇAO IN DEN ZEILTIJD
}

DOOR

W. R. MENKMAN

Thans, nu er naar gestreefd wordt dat op transatlantische zeereizen, ook op reizen naar Suriname en Curaçao, de passagiers zich zooveel mogelijk als hotelgasten zullen kunnen voelen en gedragen, lijkt het wel lang geleden dat zij die in de eerste klasse per mailboot naar of van de Nederlandsche koloniën in de West vervoerd werden, gedurende drie tot vijf weken ,en petit comité" bijeen waren in de accommodatie ,achteruit" van een klein stoomschip van 1250 tot 2250 ton bruto register; dat enkele duizenden kilos kunstijs den medegenomen voorraad versche victualie tegen bederf moesten vrijwaren en er tot aanvulling van dien voorraad gedurende den overtocht eenige levende varkens, kippen en eenden aan boord waren, soms een vaarskoetje in een hok; dat de maaltijden in den „salon” een aanvang namen zoodra de kapitein verschenen was, na vooraf den hofmeester permissie gegeven te hebben ,het eten te laten halen”.

Wel is de directe stoomvaartverbinding tusschen het moederland en Onze West pas laat (1884) tot stand gekomen, afgezien dan van den gouvernementsdienst van 1827, welke niet van langen duur is geweest, maar voor den oversteek over den oceaan was men toen al lang niet meer uitsluitend op zeilschepen aangewezen (Royal Mail Steam Packet Comp. 1839) en, vóór de opening van het Suezkanaal (1869) bestond er evenmin een ononderbroken stoomvaartverkeer tusschen Nederland en Nederlandsch Indië. De maildienst Batavia-Singapore dateert van 1845 en wie niet met een zeilschip rond de Kaap wilde gaan - een reis van vier maanden, waarvoor de passagiers zich uitrustten met een eigen voorraad levensmiddelen, eigen beddegoed en vijf dozijn hemden - kon gebruik maken van de z.g. „overlandverbinding", een onderneming door het Lid van den Raad van Indië 
J. Dupuy, tot voorlichting van na hem komende liefhebbers, nauwgezet beschreven ${ }^{1}$ ).

De Peninsular and Oriental Steam Navigation Company bevoer de trajecten Singapore-Ceylon-Aden en AlexandriëMalta-Gibraltar-Southampton; Oostenrijksche en Fransche schepen onderhielden diensten tusschen Alexandrië en Europeesche Middellandsche Zeehavens, van Malta konden passagiers met Fransche paketbooten naar Napels of Livorno reizen en vervoerden Engelsche oorlogsschepen de Indische mails naar Marseille. Het overlandvervoer geschiedde door de Egyptian Transit Comp.; tusschen Suez en Cairo met rijtuigen (voor personen) en kameelen (voor bagage en mail) en tusschen Cairo en Alexandrië met Nijlbooten (gedeeltelijk rivier-, gedeeltelijk kanaalreis).

De P. \& O. Line had op haar beide trajecten geen grootere schepen varen dan van $1500-1800$ ton, met machines van $400-500$ P.K.; de eetzaal bood zitplaatsen aan 100 passagiers, maar de badgelegenheid was zeer primitief. Bij gunstige gelegenheid liepen de schepen $10 \mathrm{mijl}$; een zeilschip maakte in die dagen vóór den wind meer vaart dan een stoomschip bij tegenwind. Natuurijs, uit Noord-Amerika aangebracht, was te Madras ook voor schepen beschikbaar; in Voor-Indië destijds een nieuwigheid, was ijs op Java nog onbekend.

Zooals voor de reis naar en van Nederlandsch-Indië ook passagiers tot 1870 van zeilschepen gebruik zijn blijven maken, om niet te hoeven overstappen, of wegens de geringere kosten, zoo heeft dit zelfde verschijnsel zich ook tot 1884 met betrekking tot de West voorgedaan; er zijn dus gedurende meer dan twee en een halve eeuw passagiers met zeilschepen van Nederland naar Curaçao en omgekeerd vervoerd.

Slechts enkele van die reizigers hebben hun ervaringen te boek gesteld; de laatste mij bekende beschrijving is vervat in een nu wel zeldzaam geworden werkje: Een spelevaart over den oceaan, door R. F. Brunings (bij Laurens van Hulst, Kampen, 1874).

Een luitenant (Granveld) gaat met een schip genaamd Argo, als geleider van een detachement van 40 soldaten en een onderofficier, naar het eiland Colchis (Curaçao) en, aangezien deze officier met hetzelfde schip naar Patria terugkeert, krijgen wij het verhaal te lezen van een uit- en een thuisreis met dezelfde gelegenheid.

1) Bijdragen tot de kennis der Nederlandsche en Vreemde Koloniën etc. $1846-1847$. 
De schrijver vertelt in het voorwoord dat Granveld's avonturen van 25 jaar geleden dagteekenen, dus de geschiedenis speelt omstreeks 1850, wat ook wel klopt met sommige mededeelingen in het verhaal zelf. Op de thuisreis maakt men zijn opwachting bij den gouverneur te Rio Hacha en deze, een jonge man van circa 30 jaar, weet zijn gasten van een bezoek aan boord van een Hollandsch oorlogsschip te vertellen, ter gelegenheid der „lijkplechtigheid „van wijlen Bolivar”; inderdaad werden in November 1842 door een der vaartuigen van het Curaçaosche eskader, $Z^{\text {r }}{ }^{\mathrm{B}}$ brik Venus, te Sta Marta honneurs bewezen bij de inscheping aldaar van het stoffelijk overschot des Bevrijders, ter overbrenging naar Venezuela. Wel spreekt Brunings van Columbia, maar hij kan in 1874 wel vergeten hebben dat de tegenwoordige republiek Colombia van 1830 tot 1863 weder Nueva Granada heette, zooals het onderkoninkrijk van den Spaanschen tijd.

Het detachement suppletietroepen voor Curaçao kwam van Harderwijk, wat ook historisch juist kan zijn, want het koloniaal werfdepôt was van 1843, reisde te water naar Amsterdam en van daar naar Rotterdam, om zich te Hellevoetsluis in te schepen; er moeten thans nog wel oud-officieren in leven zijn, wier Oost- of Westindische ervaring aangevangen is met een tocht over de Zuiderzee.

De Argo was een kof en zij voer met 10 man voor den mast; gegeven hetgeen er bekend is van het charter der toenmalige Westindiesvaarders zal zij wel minder dan 200 ton gemeten hebben. Hoewel in totaal meer dan 50 menschen over den oceaan vervoerende, had het schip alleen een "papieren” dokter aan boord.

Op Zon- en feestdagen werden blikken geopend, overigens werd in de kajuit slechts scheepkost geschaft en die was in zijn soort nog niet eens goed; de wekelijksche zakkoek was inferieur, immers zij beantwoordde niet aan den eisch van met een zeilgarentje gesneden te kunnen worden. Bij het ontbijt hard brood; melk in welken vorm dan ook had men niet aan boord. Kok en koksmaat zagen er afzichtelijk smerig uit; een hofmeester voer een kof nu eenmaal niet.

Door de medegedeelde bijzonderheden aangaande het verkennen der piek van Teneriffe en later achtereenvolgens van Marie Galante, Guadeloupe, Dominica en Martinique, kunnen wij de reis der Argonauten gemakkelijk volgen, welke overigens wel zeer weinig afwisseling bood. Eenige Engelsche schepen welke men praaide, gaven geen antwoord; bij een windstilte kreeg men 
eens bezoek van een Franschen kapitein, wiens schip in de onmiddellijke nabijheid lag te dobberen.

In de CaraibischeZee ontmoette men een geheimzinnig vaartuig, welks voorkomen en gedragingen eenige consternatie verwekte aan boord van den Argo; Brunings stelt het voor alsof men nog geloofde aan een Vliegende Hollander, het zou echter ook wel kunnen zijn dat de vrees voor zeeroovers er nog eenigszins inzat, hoewel de piraterij in dit deel der wereld geacht wordt omstreeks 1825, practisch gesproken, uitgeroeid te zijn geweest $\left.{ }^{1}\right)$. Het bekende Carabo-proces op St. Kitts had plaats in 1828 en in 1834 kon men op den Noordatlantischen Oceaan nog wel eens een verdacht uitziend schip tegenkomen ${ }^{2}$ ), zoodat een in de West onbekend koopvaardijman in de dagen van den Argo zich misschien nog niet geheel veilig voelde. Dat Westindische schepen nog bewapend waren, blijkt uit de mededeeling van Granveld, dat de schoeners met koperen stukken saluut afgaven voor het Curaçaosche fort; de Argo had alleen handvuurwapenen aan boord.

De kapitein onzer kof had op Indië gevaren en kwam voor het eerst in de Westindische wateren; met den stuurman schijnt het evenzoo te hebben gestaan. Beider wetenschappelijke ontwikkeling was volgens luitenant Granveld gelijk nul; de kapitein zou zelfs blijk gegeven hebben van nooit van den Golfstroom gehoord te hebben. Terwijl echter de schrijver zich sympathiek over stuurman Knol uitlaat, heeft hij geen woorden genoeg om zijn afkeer en minachting te uiten voor kapitein Spruit en ons diens lompheid, schijnheiligheid, ruwheid, domheid en verwaandheid te schilderen; de kofkapitein stond vijandig tegenover menschen die maatschappelijk of intellectueel zijn meerderen waren en niet tot den grootkoopmans- of reedersstand behoorden, niet het minst tegenover een ieder die uniform (vooral marine-uniform) droeg. Er manifesteert zich in het reisverhaal, van het begin tot het einde, een onoverkomenlijke antipathie tusschen twee geheel verschillende personen, die gedurende weken en weken op elkanders gezelschap waren aangewezen, de eene een welopgevoed en ontwikkeld jongmensch, de andere een bekrompen man van middelbaren leeftijd, zoolang het samenzijn duurde met het hoogste gezag bekleed. Het ergste is echter dat de schrijver den kapitein zich twee maal als een lafaard laat gedragen, eens wanneer er ge-

1) Dr. Hans Keiler, American Shipping. Probleme der Weltwirtschaft 16, Jena 1913.

2) Richard Henry Dana, Two years before the mast. 
vaar dreigt van den kant der wilde kustindianen op de reis naar Rio Hacha, later bij een zee-evenement op de thuisvaart.

Onze zeilvaart op Indië heeft, beschermd als zij werd in den tijd van cultuur- en consignatiestelsel, tot 1860 welvaart, soms zelfs groote welvaart gekend; jongelieden van goeden huize die zich gedurende deze bloeiperiode een koopvaardijloopbaan kozen, maakten snel promotie, getuigen b.v. de zeeman-koopman-litterator Van Assendelft de Coningh en de latere minister I. D. Fransen van de Putte. Matrozen echter leverde ons land niet in voldoend aantal op; de schepen waren voor twee derden met vreemdelingen bemand ${ }^{1}$ ). Voor de commercieel zooveel minder belangrijke West was toen natuurlijk weinig animo, zoowel bij de reederijen, die geen overheidssteun genoten, als bij de zeevarenden, die in de Indische vaart zooveel betere kansen hadden en zoowel wat materieel als wat personeel betreft kwam de West er slecht af, Curaçao nog slechter dan Suriname, waar nog schepen van wat grooter charter emplooi konden vinden. Zelfs kort voor de opening van den maildienst werden de zeilschepen naar Suriname ten deele met negers bemand, die echter als matrozen goed voldeden ${ }^{2}$ ).

$\mathrm{Na}$ een paar weken op Curaçao te hebben doorgebracht, ging de Argo verfhout, huiden en hoorns laden te Rio Hacha, waarmede weder drie weken gemoeid waren. Daarna ving de thuisreis aan, via de Windward-passage, want de kof kon niet voldoende scherp bij den wind opknijpen, om de Mona te bezeilen; men kon echter slechts over een oude en onbetrouwbare kaart beschikken.

Het schip strandde bij avond op het Hogsty-rif (Bahamas) en kwam er pas na twee werpankers verspeeld te hebben weder af. Ware de Argo daar gebleven, zegt Brunings, dan zou Granveld nu (1874) al twintig jaar dood zijn; dat stelt dus de reis op vijf jaar later dan uit het voorwoord afgeleid kan worden. Na nog even bijna op Groot Inagua te zijn geloopen, was men uit de misère; benoorden Bermuda gekomen liep het schip, dank zij den door den kapitein verwaarloosden Golfstroom, 80 mijl (Duitsche mijlen natuurlijk) per etmaal, d.i. het dubbele der gewone vaart. Men kwam behouden op de plaats van eerste afvaart - Hellevoet - aan; van Rio Hacha tot de Gronden had de reis zeven weken geduurd en door mist, stilte en tegenwind kon men pas na een week oponthoud het Kanaal binnenzeilen.

1) C. F. van Assendelft de Coningh, Mijn verblijf in Japan. Amsterdam 1856.

2) A. J. Riko, Ons rijk Suriname, 1883. 
Het voor mijn doel meest interessanten gedeelte van Bruning's boek is hiermede wel zoo ongeveer verteld. Wanneer hij Granveld op de uitreis een begin van een complot onder de soldaten laat ontdekken en kapitein Spruit op Curaçao aan een gastmaal een verhaal laat opdisschen over een losgebroken tijger aan boord van een van Oost-Indië thuisvarend schip, laadt hij den schijn op zich van niet origineel te zijn. Wat hij mededeelt aangaande de indianen van de kust is niet bijster belangwekkend en volkenkundig hier en daar waarschijnlijk er naast. Het romannetje van Granveld op Curaçao en de roman van den sergeant in Holland kunnen hier onbesproken blijven.

Het zou uit historisch oogpunt van belang kunnen zijn de indrukken te kennen, door iemand als Granveld op Curaçao opgedaan gedurende een vluchtig bezoek na 1848 en vóór 1855 , want dat zijn de beide uiterste grenzen welke enkele gegevens in het boek ons aan de hand doen. De Koloniale Verslagen van de jaren 1849 tot en met 1854 vermelden slechts één maal de aankomst van suppletietroepen op Curaçao, in 1854, drie detachementen, tezamen 109 onderofficieren en manschappen.

Veilig mag aangenomen worden dat Granveld op Curaçao vertoefde tijdens de bestuursperiode van gouverneur Jhr. Isaac Johannes Rammelman Elsevier Jr. Men vertelde den bezoeker dat er misstanden heerschten, maar van welken aard en omvang deze waren krijgen wij niet te hooren. Wat er over de menschen op het eiland en hun leven wordt medegedeeld verdient hier geen bespreking; erg belangwekkend of treffend is het niet.

G. B. Bosch (Reizen in West-Indië en door een gedeelte van Zuid- en Noord-Amerika, 1829-1836) is wel vaak geciteerd en nageschreven, als Curaçao-historicus, maar als reisbeschrijver staat hij wellicht hooger.

Onze dominé, die een 35 jaar eerder den oceaan overstak dan Granveld, is een man wiens antecedenten bekend zijn en die geen pseudoniemen gebruikte.

In 1815 tot predikant voor Curaçao aangesteld, maakte hij, alvorens zich naar zijn standplaats te begeven, den veldtocht in Frankrijk mede - als lid van het vrijwillige Jagerscorps der Utrechtsche studenten - en hij was niet tijdig in Holland terug om in het gevolg van den gouverneur-generaal Kikkert met het eskader onder Lewe van Aduard uit te zeilen. Zoodoende aanvaardde hij in Januari 1816 met een oude Portugeesche galjas de reis van Texel naar de West. Bosch troostte er zich mede - of 
trachtte zich zelf wijs te maken - dat men op een klein schip veiliger was dan op een groot, wat volgens hem gebleken zou zijn bij het geval van Rodney op Terceira in 1785 .

De kapitein der galjas passeerde op gevorderden leeftijd voor het eerst den keerkring, de stuurman eveneens; de eerste is bijgeloovig, bekrompen en onontwikkeld; men brengt, midden in den oceaan, bij een Franschman een visite aan boord; er is voor den passagier der galjas vrijwel niets anders te eten dan stokvisch erwten en zakkoek; de kajuit is klein, vuil en vol ongedierte. Aan de originaliteit van Bosch valt niet te twijfelen; sommige coincidenties doen de vraag rijzen of Bruning's verhaal van den Argo mogelijk niet heelemaal op de eigen ervaringen van den luitenant Granveld berust, doch hier en daar geïnspireerd is door de beschrijving der zooveel oudere reis van den dominé.

Met de navigatie aan boord van de galjas was het ook al treurig gesteld. Er was geen chronometer aan boord - zulk een instrument trof men toen alleen op oorlogsschepen en Oost-Indiëvaarders aan - en zelfs geen kijker; zelf werkte men met gegiste lengten en wanneer op een passeerend schip, dat beter voorzien was, de positie op een bord geschreven werd, kon men op de galjas de cijfers niet onderscheiden. Geen wonder dat men, door een ander gepraaid, maar deed alsof men niets zag, zooals de Engelsche schepen Iater den Argo negeerden. Er was een oud kaartenboek aan boord, dat verkeerde voorstellingen van het land gaf; des avonds werd zeil geminderd. Op zijn reis van Curaçao naar de V.S. en op zijn terugreis naar Nederland, met een Hollandsch schip, merkte Bosch op dat het bloot toeval was wanneer een schipper land zag, conform zijn bestek. Merkwaardig is de mededeeling van den schrijver dat in de Connaissance des tems (Parijs 1827) de - geographische - lengte van Curaçao als onbekend werd aangemerkt. Reeds een halve eeuw vroeger nam men aan dat het eiland gelegen is tusschen $308^{\circ} 40^{\prime}$ en $308^{\circ} 2^{\prime}$ ten opzichte der piek van Teneriffe ${ }^{1}$ ), dat is dus tusschen $51^{\circ} 20^{\prime}$ en $51^{\circ} 58^{\prime}$ ten Westen van den toenmaligen nulmeridiaan (voor de Nederlansche zeelieden althans), of tusschen $67^{\circ} 5^{\prime}$ en $68^{\circ} 43^{\prime}$ West van Greenwich. Tegenwoordig vindt men respectievelijk $68^{\circ} 44^{\prime} 30^{\prime \prime}$ en $69^{\circ} 10^{\prime} 0^{\prime \prime}$.

Op de reis van Texel naar Curaçao zeilde men bij Deseada langs de Caraibische Zee binnen (zooals ook Corn. de Jong deed in 1780 met de Mars) en deed allereerst St. Eustatius aan, waar de ma-

1) J. H. Hering, Beschrijving van het eiland Curaçao, 1779. 
trozen der Hollandsche schepen gewoon waren zich direct na aankomst aan drinken en vechten te buiten te gaan en naar de vrouwen liepen. Bosch vertelt overigens niets van de equipage; nog maar een tiental jaren eerder (1805) was Von Saek met een schip naar Suriname gereisd, waarvan de bemanning gansch onbevaren was ${ }^{1}$ ).

De Doopsgezinde kapitein der Galjas, zooals Bosch hem beschrijft, was wel een amusante kerel. Hij hield Ameland, waar hij geboren was, voor het schoonste land en boerenjongens voor den besten drank ter wereld. Van de tropen had hij geen begrip en in de warme streken voor eenige luchtverversching in het schip te zorgen kwam niet in hem op; dat had zijn oom, onder wien hij stuurman geweest was en dien hij in alles tot voorbeeld nam, ook niet gedaan, maar bij navraag bleek die oom altijd op de Oostzee en .... op Groenland gevaren te hebben. Ook in dezen tijd reeds zal de vaart op Indië wel de beste elementen tot zich getrokken hebben. De Zaankanter Engel Douwes Dekker, Eduard's vader en een tijd- en geloofsgenoot van onzen Amelander, wordt als een zeer beschaafd en beredeneerd man beschreven, met goede gezagsopvattingen ${ }^{2}$ ).

Op St. Eustatius, waar sedert het herstel der Nederlandsche souvereiniteit nog geen ander Hollandsch schip geweest was, bleef men twaalf dagen en Bosch had gelegenheid met het bedrijf van een Frieschen boer kennis te maken, die op dit tropische eiland groenten kweekte en groot vee zoowel als pluimvee hield; op Saba werd kool geplant. Bijzonderheden welke misschien van eenig belang zijn, nu het vraagstuk van den kleinen landbouw op de Bovenwindsche eilanden weder actueel is.

Men kwam behouden op Curaçao aan, maar het volgende jaar was dezelfde kapitein minder gelukkig; hij liep toen de monding der St. Annabaai voorbij, wat voor en na hem herhaaldelijk is gebeurd. Bosch wijst op het voordeel dat Bonaire had als punt van afvaart voor de reis naar Noord-Amerika of Europa; om de Westpunt van Curaçao zeilende kwam men maar al te vaak beneden de Monapassage uit.

Bosch geeft ook bijzonderheden betreffende Aruba en Bonaire, welke eilanden hij in zijn kwaliteit van predikant bezocht; de reis naar eerstgenoemd eiland ging via de St. Michielsbaai, waar men tot middernacht bleef liggen, dit in verband met het verbod om na zes uur des middags uit de St. Annabaai op Curaçao te ver-

1) Albert von Sack, Reize naar Suriname, 1821.

2) Dr. J. van den Bergh van Eysinga, Multatuli.

West Indische Gids XVI 
trekken. De kapitein die den dominé naar Aruba bracht, een inwoner van Curaçao, was, behalve vrijmetselaar, burger van vier vreemde landen; op Aruba zelf was onze reiziger getuige van een ruzie tusschen den commandant van een Colombiaansch kaperschip - een Curaçaosch kleurling - en eenige Spaansche officieren. De handel van Aruba op de Indiaansche kust was nog in vollen gang en de klassieke, 17e eeuwsche methode der ostagiërs was daarbij nog in zwang. Bosch zag herhaaldelijk kustindianen op het eiland, die veelvuldig met de schepen medekwamen, ook wel om bij de kolonisten loonarbeid te verrichten; een Engelsche bark bracht eens in B's tijd een aantal indianen als gevangenen naar Curaçao, die getracht hadden het schip af te loopen, een neiging welke zij, altijd volgens Brunings, 35 à 40 jaar later nog niet afgeleerd hadden.

In 1822 gold Bonaire nog als gunstig gelegen voor den handel op de Venezolaansche bovenkust, ook voor den sluikhandel met Puerto Cabello en La Guaira; het kunstje echter om in den nacht stilletjes smokkelgoederen van Bonaire te halen of daarheen te brengen, was in B's tijd reeds ontdekt.

Op zijn terugreis van de V.S. naar Curaçao maakte onze dominé de eigenaardige uitvaartplechtigheid mede van een aan boord overleden Amerikaansch passagier, wiens lijk in een vat brandewijn werd gekuipt; na het ,,dust thou art etc" voegden de omstanders nog een weinig brandewijn aan den inhoud van het vat toe.

Bosch repatrieerde na een bijna twaalfjarig verblijf op Curaçao. In Juni 1827 scheepte hij zich in op de brik Maria en Jacoba, kapitein J. J. Mars, bestemd naar Holland, via St. Thomas. Tusschen ultimo Juli en 1 Februari voeren geen schepen thuis, wegens de hooge assurantiepremie, in verband met het orkaangevaar. Wij weten dat er nog veel later, om dezelfde reden, gedurende zekeren tijd van het jaar ook tusschen Beneden- en Bovenwindsche eilanden slechts zelden gevaren werd, behalve dan door de mail-schoeners van den in 1850 aangevangen Westindischen paketdienst ${ }^{\mathbf{1}}$.

Op St. Thomas zag Bosch twee groote schoeners liggen, die de Hollandsche vlag misbruikten om ongestraft de slavenvaart te kunnen uitoefenen. Er kwamen op het Deensche eiland destijds zesmaal zooveel schepen als op Curaçao; wel waren de havenkosten op St. Thomas veel hooger, maar er werd oogluikend toege-

1) S. van Dissel, Bijdr. Kon. Inst. voor de taal-, land- en volkenkunde van Ned.-Indië, 1868. 
staan, uit een concurrentie-motief, dat de schepen slechts een deel hunner lading aangaven.

Ten slotte nog een veel oudere reis naar Curaçao, die van het schip Vrouw Dorothea (1746-1748), hetwelk echter de plaats van bestemming nimmer bereikte. Het verhaal der avonturen, door de opvarenden van dit schip beleefd, is vervat in een memorie, in het Algemeen Rijksarchief bewaard.

Men voer op 29 Mei 1746 van Amsterdam uit, onder kapitein Pieter Blok; er waren, behalve een equipage van 19 man, eenige passagiers aan boord.

Het schip had in April en Mei in lading gelegen en behalve „particuliere Commercianten”, had ook de „Geoctroyeerde West„Indische Compagnie dezer Landen” goederen verscheept, deze laatste geconsigneerd aan ,den Gouverneur” van Curaçao.

Men passeerde 26 Juli Tobago en kreeg den 3len Bonaire in zicht; de reis had toen dus negen weken geduurd. Door harden stroom in de bocht van Coro gedreven, kwam men ver beneden Curaçao uit, ,gelijk zulks (komt) door misleidinge van de Stroo„men of Winden veelmaalen komt te gebeuren"; besloten werd Noord-op te gaan, naar de Caicos-passage, met de bedoeling dus om de Caraibische Zee door de Windward te verlaten en natuurlijk door de Mona weder binnen te stevenen. Zoo ver is het echter niet gekomen; men vulde drinkwater en brandhout aan bij Cap Tiburon (Z.W. punt van Haïti), maar werd bij Cap Saint Nicolas (N.W. punt van Haiti) door een Engelsch oorlogsschip aangehouden. De Republiek was in den Oostenrijkschen Successie- oorlog ter zee de bondgenoote van Engeland, maar dat was voor de Britten geen reden om in de West onze schepen met rust te laten. Onze kooplieden immers trachtten, ondanks den oorlogstoestand, hun handel met de koloniën van Engeland's tegenstanders in stand te houden.

De Vrouw Dorothea werd naar Port Royal opgebracht, aldaar evenwel ten slotte vrijgegeven. Terzake van het „retardement” evenwel kon volgens de "Costuymen van het Land" geen schadevergoeding worden geëischt, evenmin ter plaatse de schade aan de lading begroot. De Britsche Admiraliteit stond toe naar Curaçao te „verzeylen”, ten einde aldaar te lossen en de schade aan de lading door een commissie te laten opnemen. Op 24 Mei 1747 men was nu al ongeveer een jaar onderweg - vertrok het schip van Port Royal, om de reis naar Curaçao te „vervorderen”. Wat er intusschen met de passagiers gebeurd was, blijkt niet; 
laten wij hopen dat zij van Jamaica spoedig een andere gelegenheid naar Curaçao hebben gevonden.

De Vrouw Dorothea immers was nog lang niet aan het einde van haar tegenspoed. Door den harden stroom bleek het niet mogelijk de Caicospassage te bezeilen, waarom de kapitein besloot door het „Canaal van Bahamaos” te gaan. Op deze reis evenwel werd het schip wederom aangehouden en wel door een Engelschen kaper, met wien men tezamen op Jamaica gelegen had. Deze kaper wenschte de Vrouw Dorothea naar Nieuw-Engeland op te brengen; de opper- en de onderstuurman echter werden gedwongen op een eveneens door den kaper buitgemaakte Spaansche bark over te gaan, waardoor kapitein Blok verstoken raakte van „genoegzaam kundige Piloten”.

Te Charlestown (Zuid-Carolina) aangekomen, begon de kaperkapitein te twijfelen of hij hier wel een voldoend willig prijsgerecht zou vinden en hij wenschte daarom maar liever weder met zijn prijs te vertrekken, naar Cape Fear, of nog verderop, naar Rhode Island. Eenige Charlestonsche kooplieden evenwel wisten gedaan te krijgen dat het vertrek belet en de zaak der Vrouw Dorothea behandeld werd.

De kaper werd in het ongelijk gesteld, maar, aangezien hij in Engeland in appèl wilde gaan, gelastte de gouverneur van ZuidCarolina lossing der lading en borgstelling. Een ander proces werd nog tegen kapitein Blok aangespannen; hij zou op Jamaica meer van de lading hebben verkocht dan hem, tot dekking der loopende kosten, toegestaan was. Het eindvonnis was: confiscatie van schip en lading ; intusschen was er op Jamaica een nieuw vonnis uitgesproken, waarbij de eerste neming gerechtvaardigd werd verklaard.

De Vrouw Dorothea is hiermede voor ons van het tooneel verdwenen; in de memorie waaraan het verhaal dezer onfortuinlijke reis ontleend is, riepen belanghebbenden de protectie der StatenGeneraal in, doch of zij succes gehad hebben weet ik niet.

Dezelfde memorie evenwel vertelt ook nog wat er van de beide stuurlieden geworden is, die zich op de Spaansche bark hadden ingescheept. Na veel omzwervingen had men daarmede koers gezet op het eiland Rotan (Ruatan of Roatan, op de kust der tegenwoordige republiek Honduras). De victualie aan boord van de bark was onvoldoende, de ratten in het schip werden gevangen en gegeten en ten slotte moest men een ouden, zieken hond slachten, om het leven te rekken. Men kwam te laag neer en liet 26 Januari 1748 het schip op de „Mosquitsche kust” loopen (thans Oostkust 
der republiek Nicaragua); het blijkt echter dat men boven kaap Gracias a Dios was, want door 70 mijl te roeien kon men „Black Rivier" (Rio Negro, tegenwoordige republiek Honduras) bereiken. Hier vond men scheepsgelegenheid naar Ruatan en van laatstgenoemd eiland vertrok men naar Engeland. Van Bristol met een Noorsch schip naar Hamburg en van daar met een tjalk naar Amsterdam gereisd hebbend, waren de beide stuurlieden op 13 Juli 1748, dus na ruim twee jaar, op de plaats van eerste afvaart terug, zonder Curaçao, waarheen men 29 Mei 1746 uitgezeild was, gezien te hebben.

De zeilvaart is tot de geschiedenis gaan behooren en het is aardig om thans, nu op verkeersgebied de toestanden zoo ten eene male veranderd zijn, nog eens de ervaringen mede te beleven van hen die vroeger met zeilschepen naar onze koloniën reisden.

Ook de koloniale litteratuur echter is niet meer dezelfde als voorheen, toen gewezen landsdienaren nogal eens naar de pen grepen, om aan het moederlandsche publiek te vertellen hoe het er in onze overzeesche gebieden uitzag en wat daar al zoo gebeurde, hetgeen dan tevens een gelegenheid was om de reizen naar en van die gebieden te beschrijven. Ambtenaren en militairen die een langdurigen Indischen loopbaan achter den rug hadden, waren op de maandenlange reizen met zeilschepen van en naar het moederland in nauwe aanraking geweest met het personeel aan boord en zijn werkzaamheden, hadden als het ware mee "gevaren".

Persoonlijke ervaringen van hen die Westindische zeereizen gemaakt hebben, nadat Nederland had opgehouden deelnemer te zijn aan den strijd der Europeesche naties in de Nieuwe Wereld, maar vóórdat de allereerste pogingen werden gedaan om een tocht over den oceaan inderdaad tot een spelevaart te maken, verdienen aan de vergetelheid te worden onttrokken, ook omdat zij tamelijk zeldzaam zijn.

November 1934. 